\title{
Produção de forragem e de grãos de trigo de duplo propósito submetido a diferentes densidades de semeadura, adubação nitrogenada e manejos de corte
}

\author{
Forage and grain production of dual-purpose wheat under different sowing densities, nitrogen fertilizer levels \\ and cuts managements
}

\section{Marcio Zilio*, Jéssica Aline Peloso e Analu Mantovani}

Submissão: 30/03/2016 / Aceite: 17/04/2017

\section{RESUMO}

O objetivo do trabalho foi avaliar a produção de forragem e a produtividade de grãos, em cultivar de trigo de duplo propósito, submetidos a diferentes doses de nitrogênio, regimes de corte e densidades de semeadura. Utilizou-se o delineamento experimental inteiramente casualizado, com quatro repetições, em um arranjo fatorial (densidade de semeadura $\mathrm{x}$ doses de nitrogênio), nas parcelas principais, com parcelas subdivididas (manejos de corte). As densidades de semeadura utilizadas foram de 400 e 500 sementes aptas por $\mathrm{m}^{2}$. As doses de nitrogênio foram de 100 , 150, 200, 250 e $300 \%$ da dose recomendada, aplicados na base, no perfilhamento e após cada corte. As subparcelas foram divididas conforme o manejo de corte (sem corte, um corte e dois cortes). O segundo corte proporcionou maior acúmulo de forragem, não causou prejuízos à composição mineral e ao teor de proteína bruta e também não reduziu a produtividade. No manejo com dois cortes a adubação nitrogenada deve ser superior (2,5 vezes) à adubação recomendada, pois aumenta a produção de forragem. A maior densidade de semeadura promoveu incrementos na produtividade de grãos e não alterou a produção de forragem no segundo corte. O teor de proteína bruta na forragem não foi alterado pelo manejo adotado.

\section{PALAVRAS-CHAVE: Triticum aestivum,} produtividade de grãos, biomassa, manejo de produção.

\section{ABSTRACT \\ The aim of this study was to evaluate the forage yield and grain productivity of dual-purpose wheat under different nitrogen fertilizer levels, harvesting}

managements and sowing densities. The experimental design was a completely randomized with four repetitions and had a factorial treatment arrangement (sowing density vs. nitrogen level) with sub-parcels (harvesting management). The sowing densities were 400 and 500 viables seed $\mathrm{m}^{-2}$. Nitrogen levels were $100,150,200,250$ and $300 \%$ of recommended levels, applied on the base during tillering and after each harvest. The split-plot-parcels were divided according to harvesting management (zero, one and two cuts). Two consecutive cuts provided greater forage accumulation, without affect mineral composition, crude protein content and productivity. Nitrogen fertilizer level must be 2.5 times higher for two harvest level, because increase forage yield. The greater sowing density increased grain productivity but did not affect forage yield in second harvest. The treatments did not change crude protein content.

KEYWORDS: Triticum aestivum, grain yield, biomass, regimes production.

\section{INTRODUÇÃO}

Na região Sul do Brasil, no início do outono, ocorre uma limitação da quantidade e qualidade da forragem fornecida (WENDT et al. 2006). Devido a essa sazonalidade na produção de forragem, a implantação de pastagens para alimentação do gado nesse período vem sendo utilizada como alternativa viável para o aproveitamento de áreas normalmente ocupadas pela produção de grãos no verão (FEROLLA et al. 2010). Neste sentido, a utilização de pastagens anuais de inverno em áreas tradicionais de agricultura tem conduzido à atividade de integração lavourapecuária, que pode resultar em melhor aproveitamento do potencial da propriedade. 
O sistema de integração lavoura-pecuária mais comum no Sul do Brasil consiste em concentrar a produção de grãos no período quente do ano, principalmente com soja e milho, e a produção animal no inverno, usando principalmente aveias e azevém (BALBINOT JUNIOR et al. 2009). Outra opção de fornecimento de forragens aos animais é o uso de cereais de duplo propósito, que servem para fornecer forragem aos animais até um determinado momento e, posteriormente, a cultura é destinada para produção de grãos. Assim, uma gramínea de dupla aptidão que pode ser utilizada no inverno é o trigo, objetivando principalmente a produção de grãos, mas podendo ser utilizado também como forragem para os animais dentro do mesmo cultivo (MARTIN et al. 2010).

As cultivares de trigo de duplo propósito devem apresentar ciclo vegetativo longo e ciclo reprodutivo curto, fornecer elevada produção de forragem e alta capacidade de rebrote, para recuperar a parte aérea que dará suporte a produção de grãos (SCHEFFERBASSO et al. 2001). Para alguns cultivares de trigo, pode ocorrer redução na produção de grãos após cortes consecutivos, bem como do valor do peso de hectolitro e da massa de mil sementes. Segundo BORTOLINI et al. (2004), no sistema de um corte, considerável quantidade de forragem pode ser removida, sem afetar seriamente a produção de grãos. Este comportamento não se repete na utilização de manejo com dois cortes. Porém, DEL DUCA et al. (2000) observaram que trigo de duplo propósito, após ser pastejado, produz rendimento de grãos similar ou até superior do que o não pastejado, em virtude de vários fatores, como elevado afilhamento, renovada área foliar e redução de porte, permitindo maior contribuição fotossintética ao crescimento da planta e redução do número de plantas acamadas.

Além dos fatores citados anteriormente, a densidade de semeadura também influencia diretamente a produção de perfilhos (WENDT et al. 2006, MARTIN et al. 2010) e consequentemente a produção de forragem e grãos (ZAFFARONI et al. 1998). O aumento da densidade de semeadura pode ser uma estratégia adotada para antecipar os cortes, diminuindo assim o vazio forrageiro de outono (MARTIN et al. 2010). Outro aspecto relacionado à capacidade de rebrote e emissão de perfilhos é o estado nutricional da planta, especialmente no que se refere ao nitrogênio. No trigo de duplo propósito maiores doses de nitrogênio podem ser utilizadas para aumentos de produção de forragem e grãos sem apresentar o risco de acamamento em razão da redução do seu porte provocado pelos cortes.

Além da quantidade, a qualidade da forragem produzida pelos cereais de inverno é determinada por diversos fatores, como o manejo adotado e sua adaptabilidade às diferentes condições edafoclimáticas (MEINERZ et al. 2011). Nesse aspecto, a produção de forragem com elevado teor de proteína bruta e a composição da fração mineral no período outonal, são parâmetros importantes na escolha do manejo para os cereais de duplo propósito.

A fim de que as atividades de integração lavoura-pecuária contribuam efetivamente para uma exploração mais racional do potencial da propriedade, torna-se necessário ampliar o conhecimento do manejo de duplo propósito. O número de cortes realizado depende da região, pois estas são determinadas por aspectos fenológicos da cultura e estes, por sua vez, são influenciados por variáveis climáticas e de manejo, principalmente disponibilidade de nitrogênio e densidade de semeadura. A avaliação conjunta desses fatores torna-se importante para estabelecer indicações de manejo para o trigo de duplo propósito. Portanto o objetivo do trabalho foi avaliar a produção de forragem e a produtividade de grãos, em trigo de duplo propósito, cultivar BRS Tarumã submetido a diferentes doses de nitrogênio, regimes de corte e densidades de semeadura.

\section{MATERIAL E MÉTODOS}

O experimento foi conduzido no munícipio de Joaçaba, SC, na safra de inverno de 2015 no sistema de plantio direto em sucessão a cultura da soja. O delineamento experimental foi inteiramente casualizados, com quatro repetições, em que os tratamentos foram distribuídos em um arranjo fatorial (densidade de semeadura $\mathrm{x}$ doses de nitrogênio), nas parcelasprincipais, comparcelassubdivididas(manejos de corte). As densidades de semeadura utilizadas foram de 400 e 500 sementes por metro quadrado. As doses de nitrogênio foram de $100 \%\left(60 \mathrm{~kg} \mathrm{ha}^{-1}\right), 150 \%$ (90 kg ha-1), 200\% (120 kg ha-1), 250\% (150 kg ha-1) e 300\% (180 $\left.\mathrm{kg} \mathrm{ha}^{-1}\right)$ da dose recomendada para uma expectativa de rendimento de $4000 \mathrm{~kg} \mathrm{ha}^{-1}$. As subparcelas foram divididas conforme o manejo de corte (sem corte, um corte e dois cortes). Realizouse o corte quando o trigo atingiu uma altura de 30 $\mathrm{cm}$, sendo deixado um resíduo de $10 \mathrm{~cm}$ do solo. A parcela experimental foi constituída de cinco fileiras 
com espaçamento entrelinhas de $17 \mathrm{~cm}$, por $5 \mathrm{~m}$ de comprimento e área útil das subparcelas foi composta por três fileiras centrais de $1 \mathrm{~m}$ de comprimento. A cultivar de trigo utilizada foi BRS Tarumã. A análise inicial do solo apresentou teor de argila de $540 \mathrm{~g} \mathrm{~kg}^{-1}$, matéria orgânica de $54 \mathrm{~g} \mathrm{~kg}^{-1}$, CTC do solo a pH 7,0 de $22,6 \mathrm{cmol}_{\mathrm{c}} \mathrm{dm}^{-3}$ e $\mathrm{pH}$ em água de 5,5 . Os teores iniciais dos nutrientes foram $\mathrm{Ca}=8,9 \mathrm{cmol}_{\mathrm{c}} \mathrm{dm}^{-3}$, $\mathrm{Mg}=4,0 \mathrm{cmol}_{\mathrm{c}} \mathrm{dm}^{-3}, \mathrm{P}=33,1 \mathrm{mg} \mathrm{dm}^{-3}, \mathrm{~K}=425,5 \mathrm{mg}$ $\mathrm{dm}^{-3}, \mathrm{H}+\mathrm{Al}=8,6 \mathrm{cmol}_{\mathrm{c}} \mathrm{dm}^{-3}$ e $\mathrm{Al}=0,0 \mathrm{cmol}_{\mathrm{c}} \mathrm{dm}^{-3}$. A semeadura foi realizada no dia $05 / 06 / 2015$. O controle de plantas daninhas e os tratamentos fitossanitários obedeceram às indicações técnicas da cultura. Os valores médios de precipitação pluvial, temperaturas mínima, média e máxima referentes aos meses de junho a novembro, são apresentados na Figura 1.

A adubação nitrogenada em cobertura foi parcelada da seguinte forma: na subparcela onde não houve corte, a dose integral foi feita em uma única aplicação, por ocasião do início do perfilhamento; nas subparcelas referentes ao regime de um corte as doses foram aplicadas em duas parcelas iguais, aplicadas no perfilhamento e imediatamente após o corte; e, na subparcela referente ao regime de dois cortes, foram três parcelas iguais, aplicadas no perfilhamento e após cada um dos dois cortes. As doses de nitrogênio em cobertura foram aplicadas a lanço, sendo utilizada como fonte de $\mathrm{N}$ mineral a ureia $(45 \%$ de $\mathrm{N})$. Todas as subparcelas receberam $20 \mathrm{~kg} \mathrm{ha}^{-1}$ no momento da semeadura.

Cortou-se toda a área útil de cada subparcela para estimar o rendimento de forragem $\left(\mathrm{kg} \mathrm{ha}^{-1}\right)$, quando as plantas atingiram aproximadamente $30 \mathrm{~cm}$ de altura, realizando-se corte manual, a $10 \mathrm{~cm}$ da superfície do solo. Para determinar a matéria seca, a amostra coletada foi seca em estufa a $60^{\circ} \mathrm{C}$ até peso constante. Para a produção de forragem, foram utilizadas apenas as subparcelas que receberam os regimes de um e de dois cortes. Após a colheita foram realizadas na área útil de cada subparcela as seguintes avaliações: massa de espigas, peso de mil grãos, número de grãos por espiga, número de espiguetas, número de grãos por espigueta, comprimento de espiga e produção de grãos (ajustada para 13\% de umidade). Os componentes de produção foram determinados a partir da coleta, ao acaso, de 10 espigas de trigo, por parcela.

A amostra de forragem seca em estufa foi moída a $1 \mathrm{~mm}$ em moinho tipo Willey e acondicionada em sacos plásticos para posterior determinação de proteína bruta, fósforo, potássio, cálcio e magnésio.
A determinação de $\mathrm{P}, \mathrm{K}, \mathrm{Ca}$ e $\mathrm{Mg}$ foram realizadas de acordo com a metodologia de TEDESCO et al. (1995). O teor de nitrogênio total foi determinado pelo método Kjeldahl (AOAC 1995). Para determinação do teor de proteína bruta foi utilizado o fator de 6,25 $\mathrm{x}$ o valor de nitrogênio total da amostra.

Os dados foram submetidos à análise de variância $\mathrm{F}$ e, quando detectadas variações significativas, as médias foram comparadas pelo teste de Tukey a 5\% de probabilidade. Os efeitos da interação também foram testados na análise de regressão, por meio do teste da significância dos distintos graus do polinômio.

\section{RESULTADOS E DISCUSSÃO}

As condições climáticas adversas atrasaram o período de semeadura do trigo para está finalidade, que normalmente ocorre nos meses de abril e maio. As condições também não foram favoráveis para o crescimento da cultura (Figura 1). O excesso de chuvas, temperaturas altas que reduziram o período de perfilhamento e aceleraram o alongamento da cultura e a ocorrência de geada tardia durante o emborrachamento, reduziram a produção de forragem e a produtividade de grãos.

Não houve interação significativa entre as doses de nitrogênio, densidade de semeadura e manejo dos cortes para a maioria das características avaliadas. Apenas houve interação para a produção de forragem entre a adubação nitrogenada e manejo dos cortes da forragem e interação significativa entre densidade de semeadura e manejo de cortes.

Considerando o fator nitrogênio os componentes da produção, peso de espiga, número de espiguetas por espiga, número de grãos por espiga e peso de grãos por espiga apresentaram diferença significativa (Tabela 1). Para estes componentes da produção a dose de nitrogênio que apresentou a maior resposta foi a de 200\% (20 kg ha-1 na base $+100 \mathrm{~kg} \mathrm{ha}^{-1} \mathrm{em}$ cobertura). As doses mais elevadas de nitrogênio apresentaram redução nos componentes da produção, especialmente número e peso de grãos por espiga. A dose de nitrogênio não interferiu na produtividade de grãos. Tal resultado deveu-se ao elevado teor de matéria orgânica no solo e a baixa produtividade de grãos que foi limitada pelas condições climáticas durante o período de cultivo. 


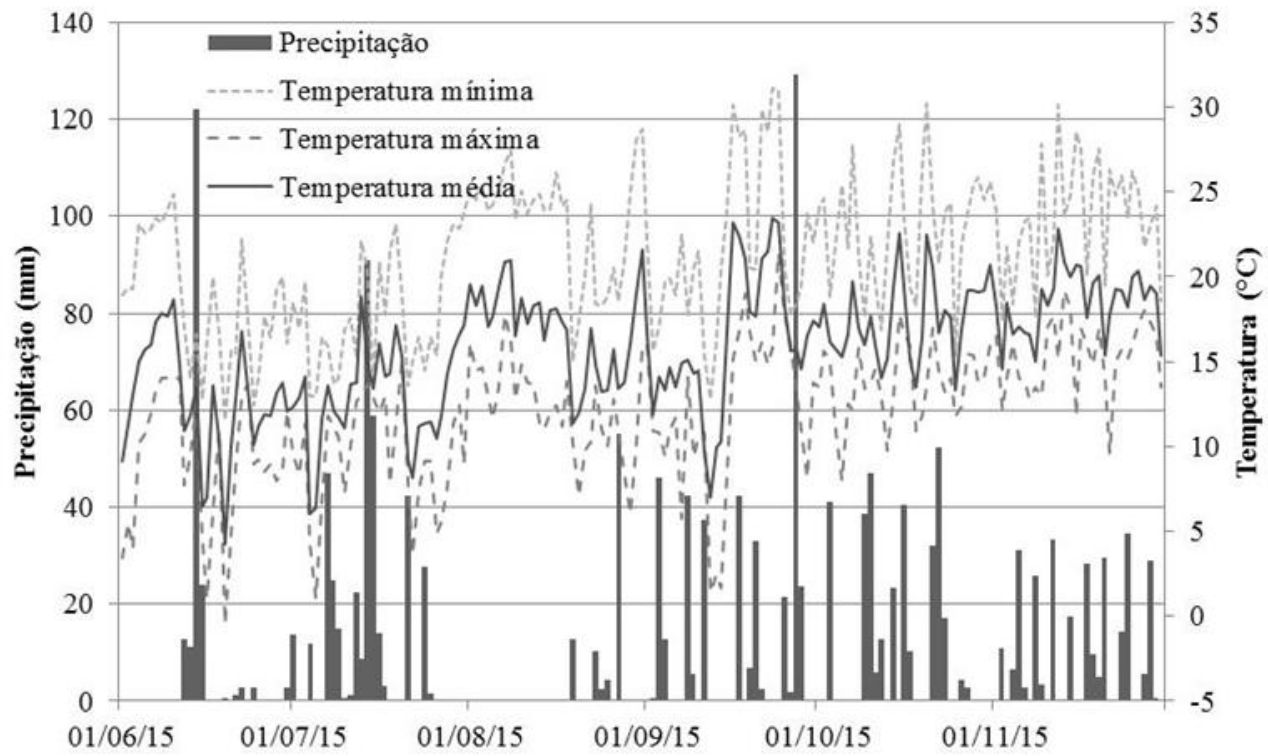

Figura 1. Dados relativos à precipitação pluvial, às temperaturas mínima, média e máxima durante o cultivo do trigo de duplo propósito BRS Tarumã, em Joaçaba, SC.

Figure 1. Rainfall, minimum, mean and maximum temperatures during of BRS Tarumã dual-purpose wheat cropping, Joaçaba, SC.

Tabela 1. Efeito de doses de nitrogênio no rendimento de grãos e componentes da produção em trigo de duplo propósito BRS Tarumã.

Table 1. Effect of nitrogen levels on grain yield and componens yield of BRS Tarumã dual-purpose wheat.

\begin{tabular}{|c|c|c|c|c|}
\hline Dose de N $(\%)$ & $\mathrm{CE}(\mathrm{cm})$ & $\mathrm{PE}(\mathrm{g})$ & NEE & NGE \\
\hline 100 & 4,3 & $0,69 \mathrm{~B}$ & $10,58 \mathrm{~B}$ & $19,23 \quad$ В \\
\hline 150 & 4,2 & $0,70 \mathrm{AB}$ & $10,97 \mathrm{AB}$ & $19,22 \quad \mathrm{~B}$ \\
\hline 200 & 4,7 & 0,79 A & $11,99 \mathrm{~A}$ & $21,33 \mathrm{~A}$ \\
\hline 250 & 4,3 & $0,71 \quad \mathrm{AB}$ & $11,45 \mathrm{AB}$ & $19,41 \quad$ B \\
\hline 300 & 4,3 & $0,71 \quad \mathrm{AB}$ & $10,43 \quad \mathrm{~B}$ & $18,36 \mathrm{~B}$ \\
\hline CV (\%) & 6,47 & 14,52 & 11,18 & 12,99 \\
\hline $\mathrm{F}_{\text {(tratamento) }}$ & $2,44^{\mathrm{ns}}$ & $3,23 *$ & $5,01 *$ & $4,68^{*}$ \\
\hline Dose de N (\%) & PGE (g) & $\mathrm{P} 1000(\mathrm{~g})$ & NGET & PG $\left(\mathrm{kg} \mathrm{ha}^{-1}\right)$ \\
\hline 100 & $0,502 \mathrm{AB}$ & 25,96 & 1,83 & 1227,5 \\
\hline 150 & 0,498 В & 25,88 & 1,75 & 1463,9 \\
\hline 200 & $0,571 \mathrm{~A}$ & 26,76 & 1,78 & 1410,3 \\
\hline 250 & 0,499 B & 25,65 & 1,70 & 1324,8 \\
\hline 300 & $0,490 \quad \mathrm{~B}$ & 26,67 & 1,78 & 1508,3 \\
\hline CV (\%) & 16,85 & 9,09 & 12,51 & 25,72 \\
\hline $\mathrm{F}_{\text {(tratamento) }}$ & $3,68^{*}$ & $0,95^{\mathrm{ns}}$ & $1,22^{\mathrm{ns}}$ & $1,76^{\mathrm{ns}}$ \\
\hline
\end{tabular}

Médias seguidas da mesma letra maiúscula nas colunas não diferem $(\mathrm{p}<0,05)$ significativamente pelo teste Tukey.

ns Não significativo. *Significativo a $5 \%$ de probabilidade. Componentes da produção: CE, comprimento de espiga; PE, peso de espiga; NEE, número de espiguetas por espiga; NGE, número de grãos por espiga; PGE, peso de grãos por espiga; P1000, peso de mil grãos; NGET, número de grãos por espigueta; PG, produtividade de grãos. 
Com base no número de cortes, as características de comprimento de espiga, peso de espiga, número de espiguetas por espiga, número de grãos por espiga e peso de grãos por espiga apresentaram resposta diferenciada (Tabela 2). Houve redução do tamanho e peso de espiga quando a planta de trigo foi submetida a 1 e 2 cortes comparada quando não foi realizado o corte das plantas. A desfolha reduz a área foliar e afeta a redistribuição de fotoassimilados que a planta utiliza na fase reprodutiva (BORTOLINI et al. 2004). Além disso, a remoção do ápice reprodutivo provocado pelos cortes durante a elongação dos colmos, possivelmente reduziu o tamanho das espigas (BORTOLINI et al. 2004). O menor tamanho e peso da espiga é reflexo do menor número de espiguetas por espiga, observados nos tratamentos que sofreram os cortes. Quando a desfolha foi mais severa (2 cortes) o número de espiguetas foi menor. Com a redução do número de espiguetas houve redução no número e peso de grãos por espiga. Portanto, a desfolha promove redução nestes componentes da produção e essa redução é mais severa quanto maior for o número de cortes. Segundo MARTIN et al. (2010) apesar dos materiais BRS Figueira, BRS Guatambu, BRS Tarumã e BRS Umbu serem considerados de dupla aptidão, os componentes de produção e a produtividade de grãos foram drasticamente reduzidas, indicando que sua recomendação como cereal de dupla aptidão deve ser revisada, ou as alturas do corte e o estabelecimento do momento do corte devem ser mais avaliados.

Apesar da redução dos componentes do rendimento com a desfolha, a produção de grãos não foi afetada. Com o uso de manejo adequado, considerável quantidade de forragem pode ser removida, sem afetar seriamente a produção de grãos. De acordo com BORTOLINI et al. (2004) todos os cereais de duplo propósito testados, apresentaram melhoria significativa do peso do hectolítro quando estes sofreram um corte, provavelmente pela redução do índice de acamamento, resultando em grãos mais pesados. SCHEFFER-BASSO et al. (2001), concluíram que a produtividade de grãos pode ser incrementada pela redução no acamamento. De acordo com CHRISTIANSEN et al. (1989), a desfolha pode aumentar a produtividade de grãos ao reduzir o acamamento, desde que o tempo e a intensidade de pastejo não sejam severos.

A densidade de semeadura não apresentou efeito sobre os componentes da produção, com exceção do peso de 1000 grãos onde a maior densidade de semeadura promoveu maior enchimento dos grãos (Tabela 3). O aumento na densidade de semeadura

Tabela 2. Efeito do manejo de corte no rendimento de grãos e componentes da produção em trigo de duplo propósito BRS Tarumã.

Table 2. Cuts management effect on grain yield and components yield of BRS Tarumã dual-purpose wheat.

\begin{tabular}{|c|c|c|c|c|}
\hline Manejo & $\mathrm{CE}(\mathrm{cm})$ & $\mathrm{PE}(\mathrm{g})$ & NEE & NGE \\
\hline Sem corte & $4,6 \mathrm{~A}$ & $0,82 \mathrm{~A}$ & $12,42 \mathrm{~A}$ & $22,39 \quad \mathrm{~A}$ \\
\hline 1 corte & $4,1 \quad \mathrm{~B}$ & $0,69 \mathrm{~B}$ & $10,82 \mathrm{~B}$ & $19,22 \mathrm{~B}$ \\
\hline 2 cortes & $4,2 \mathrm{~B}$ & $0,65 \mathrm{~B}$ & $10,01 \mathrm{C}$ & $16,92 \mathrm{C}$ \\
\hline CV $(\%)$ & 6,47 & 14,52 & 11,18 & 12,99 \\
\hline $\mathrm{F}_{\text {(tratamento) }}$ & $39,51 *$ & $29,21 *$ & $39,13 *$ & $47,09^{*}$ \\
\hline Manejo & PGE (g) & $\mathrm{P} 1000(\mathrm{~g})$ & NGET & PG $\left(\mathrm{kg} \mathrm{ha}^{-1}\right)$ \\
\hline Sem corte & $0,594 \mathrm{~A}$ & 26,51 & 1,81 & 1347,4 \\
\hline 1 corte & $0,497 \quad \mathrm{~B}$ & 25,70 & 1,79 & 1430,5 \\
\hline 2 cortes & $0,445 \mathrm{C}$ & 26,34 & 1,70 & 1383,0 \\
\hline CV $(\%)$ & 16,85 & 9,09 & 12,51 & 25,72 \\
\hline $\mathrm{F}_{\text {(tratamento) }}$ & $30,90 *$ & $1,30^{\mathrm{ns}}$ & $2,77^{\mathrm{ns}}$ & $1,35^{\mathrm{ns}}$ \\
\hline
\end{tabular}

Médias seguidas da mesma letra maiúscula nas colunas não diferem $(\mathrm{p}<0,05)$ significativamente pelo teste Tukey.

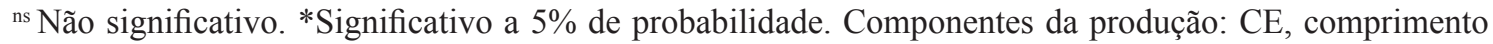
de espiga; PE, peso de espiga; NEE, número de espiguetas por espiga; NGE, número de grãos por espiga; PGE, peso de grãos por espiga; P1000, peso de mil grãos; NGET, número de grãos por espigueta; PG, produtividade de grãos. 
proporcionou incremento na produtividade de grãos de aproximadamente $241 \mathrm{~kg} \mathrm{ha}^{-1}$. O maior rendimento pode ser atribuído ao maior número de plantas, e o maior peso de 1000 grãos pode ser explicado, em parte, pela menor participação de grãos advindos de perfilhos secundários, que apresentam menor peso quando comparados aos grãos de perfilhos principais (BORTOLINI et al. 2004).

A maior produção de forragem ocorreu na densidade de 500 sementes $/ \mathrm{m}^{2}\left(1162,8 \mathrm{~kg} \mathrm{ha}{ }^{-1}\right)$ em relação a 400 sementes $/ \mathrm{m}^{2}\left(1051,0 \mathrm{~kg} \mathrm{ha}{ }^{-1}\right)$. O segundo corte apresentou aumento da produção de forragem, para ambas as densidades de semeadura (Tabela 4). Segundo BORTOLINI et al. (2004), o aumento no rendimento de forragem se expressa pela alta capacidade de rebrote, atividade de indução na formação de novos perfilhos. SCHEFFER-BASSO et al. (2001) trabalhando com 21 genótipos de aveia, observaram redução no número de perfilhos no segundo corte para a aveia-preta comum. De acordo com os resultados de MEINERZ et al. (2012), o trigo BRS Tarumã mostrou aumento na produção de forragem no segundo corte em comparação ao primeiro.

Adensidade de semeadura afetou positivamente a produção de forragem apenas quando foi realizado o primeiro corte (Tabela 4). A maior densidade de semeadura mostrou tendência de aumento da produção de forragem em relação a menor população de plantas $\left(\approx 175 \mathrm{~kg} \mathrm{ha}^{-1}\right)$. No entanto, no corte posterior não foi observado diferença na produção de forragem quando aumentou a densidade de semeadura. Tal fato possivelmente está relacionado ao máximo perfilhamento do trigo no período do segundo corte o que compensou a menor densidade de semeadura. A capacidade de perfilhamento ocorre por diversos fatores, inclusive pela coordenação e pelo sincronismo entre o desenvolvimento de folhas e o perfilhamento, conhecido como ocupação de sítios (VALÉRIO et al. 2008). Segundo MARTIN et al. (2010), a maior densidade de semeadura reduziu o número de perfilhos em trigos de duplo propósito. VALÉRIO et al. (2008) ressaltam que é preciso adequar a densidade de semeadura pra potencializar a produção de perfilhos.

Para a produção de forragem as aplicações de nitrogênio acima de $200 \%$ (20 $\mathrm{kg} \mathrm{ha}^{-1}$ na base + $100 \mathrm{~kg} \mathrm{ha}^{-1} \mathrm{em}$ cobertura) favoreceram o aumento da produção de matéria seca do segundo corte (Tabela 5). O fornecimento dividido em três parcelas iguais, aplicadas no perfilhamento e após cada um dos dois cortes, possibilitou maior acúmulo de forragem em doses acima de $120 \mathrm{~kg} \mathrm{ha}^{-1}$. Não foi observado diferença entre o manejo de apenas um corte e o primeiro corte do sistema manejado com dois cortes, mesmo este apresentando apenas parte da adubação

Tabela 3. Efeito da densidade de semeadura no rendimento de grãos e componentes da produção em trigo de duplo propósito BRS Tarumã.

Table 3. Effect of sowing density on grain yield and components yield of BRS Tarumã dual-purpose wheat.

\begin{tabular}{lcccc}
\hline Densidade de semeadura $\left(\mathrm{m}^{2}\right)$ & $\mathrm{CE}(\mathrm{cm})$ & $\mathrm{PE}(\mathrm{g})$ & $\mathrm{NEE}$ & NGE \\
\hline 400 & 4,3 & 0,72 & 11,28 & 19,77 \\
500 & 4,3 & 0,72 & 10,87 & 19,25 \\
\hline $\mathrm{CV}(\%)$ & 6,47 & 14,52 & 11,18 & 12,99 \\
$\mathrm{~F}_{\text {(tratamento) }}$ & $0,14^{\mathrm{ns}}$ & $0,07^{\mathrm{ns}}$ & $2,34^{\mathrm{ns}}$ & $1,30^{\mathrm{ns}}$ \\
\hline Densidade de semeadura $\left(\mathrm{m}^{2}\right)$ & $\mathrm{PGE}(\mathrm{g})$ & $\mathrm{P} 1000(\mathrm{~g})$ & $\mathrm{NGET}^{\mathrm{N}}$ & $\mathrm{PG}\left(\mathrm{kg} \mathrm{ha}^{-1}\right)$ \\
\hline 400 & 0,505 & $24,46 \mathrm{~B}$ & 1,77 & $1266,2 \mathrm{~B}$ \\
500 & 0,520 & $26,91 \mathrm{~A}$ & 1,77 & $1507,6 \mathrm{~A}$ \\
\hline $\mathrm{CV}(\%)$ & 16,85 & 9,09 & 12,51 & 25,72 \\
$\mathrm{~F}_{\text {(tratamento) }}$ & $0,89^{\mathrm{ns}}$ & $10,15^{*}$ & $0,01^{\mathrm{ns}}$ & $10,18^{*}$ \\
\hline
\end{tabular}

Médias seguidas da mesma letra maiúscula nas colunas não diferem $(\mathrm{p}<0,05)$ significativamente pelo teste Tukey.

ns Não significativo. *Significativo a $5 \%$ de probabilidade. Componentes da produção: CE, comprimento de espiga; PE, peso de espiga; NEE, número de espiguetas por espiga; NGE, número de grãos por espiga; PGE, peso de grãos por espiga; P1000, peso de mil grãos; NGET, número de grãos por espigueta; PG, produtividade de grãos. 
Tabela 4. Rendimento de forragem em resposta a densidade de semeadura e manejo de cortes em trigo de duplo propósito BRS Tarumã.

Table 4. Forage yield in different sowing densities and harvesting managements of BRS Tarumã dual-purpose wheat.

\begin{tabular}{lrr}
\hline \multicolumn{4}{c}{ Rendimento de matéria seca $\left(\mathrm{kg} \mathrm{ha}^{-1}\right)$} \\
\hline \multirow{2}{*}{ Manejo } & \multicolumn{3}{c}{ Densidade de semeadura $\left(\mathrm{m}^{2}\right)$} \\
\hline \multirow{2}{*}{ corte } & 400 & \multicolumn{1}{c}{500} \\
2 cortes $\left(1^{\circ}\right)$ & $904,5 \mathrm{Bb}$ & $1100,2 \mathrm{Ba}$ \\
2 cortes $\left(2^{\circ}\right)$ & $835,8 \mathrm{Ba}$ & $989,5 \mathrm{Ba}$ \\
\cline { 2 - 4 } & $1432,7 \mathrm{Aa}$ & $1381,9 \mathrm{Aa}$ \\
\hline
\end{tabular}

Médias seguidas da mesma letra minúscula nas linhas e maiúscula nas colunas não diferem $(p<0,05)$ significativamente pelo teste Tukey.

Tabela 5. Rendimento de forragem em resposta a adubação nitrogenada e manejo de cortes em trigo de duplo propósito BRS Tarumã.

Table 5. Forage yield in different nitrogen levels and harvesting managements of BRS Tarumã dual-purpose wheat.

\begin{tabular}{|c|c|c|c|c|c|}
\hline \multicolumn{6}{|c|}{ Rendimento de matéria seca $\left(\mathrm{kg} \mathrm{ha}^{-1}\right)$} \\
\hline \multirow{2}{*}{ Manejo } & \multicolumn{5}{|c|}{ Nitrogênio (\%) } \\
\hline & 100 & 150 & 200 & 250 & 300 \\
\hline 1 corte & $1075,7 \mathrm{~A}$ & $974,7 \mathrm{~A}$ & $852,7 \mathrm{~B}$ & $1058,9 \mathrm{~B}$ & $1046,5 \mathrm{~B}$ \\
\hline 2 cortes $\left(1^{\circ}\right)$ & $1023,1 \mathrm{~A}$ & $846,4 \mathrm{~A}$ & $819,5 \mathrm{~B}$ & $825,2 \mathrm{~B}$ & $996,7 \mathrm{~B}$ \\
\hline 2 cortes $\left(2^{\circ}\right)$ & $1141,9 \mathrm{~A}$ & $1245,3 \quad \mathrm{~A}$ & $1439,8 \quad \mathrm{~A}$ & $1619,3 \mathrm{~A}$ & $1540,3 \mathrm{~A}$ \\
\hline
\end{tabular}

Médias seguidas da mesma letra maiúscula nas colunas não diferem $(\mathrm{p}<0,05)$ significativamente pelo teste Tukey.

nitrogenada em cobertura (1/3 da dose de cobertura). Este resultado possivelmente deveu-se ao trigo ter sido cultivado após a soja e o solo apresentar elevado teor de matéria orgânica, o que disponibilizou maior teor de nitrogênio pela mineralização e decomposição.

De acordo com a análise de regressão, o rendimento de matéria seca apresentou aumento linear significativo com o incremento na dose de nitrogênio apenas para o $2^{\circ}$ corte (Figura 2). Isto demonstra que incrementos nas doses de nitrogênio aplicadas no perfilhamento e após cada um dos dois cortes aumentam a produção de forragem no $2^{\circ}$ corte.

A proteína bruta na forragem não diferiu em relação às doses de nitrogênio, densidade de semeadura e manejo dos cortes, sendo que os valores médios foram próximos a $24 \%$ (Tabela 6 ). MEINERZ et al. (2011), que, avaliando genótipos de trigo submetidos a 3 cortes, observaram valores médios entre $24,22 \%$ ( $1^{\circ}$ corte), $22,8 \%$ ( $2^{\circ}$ corte $)$ e $15,6 \%$ ( $3^{\circ}$ corte) de proteína bruta. Os teores observados foram superiores aos relatados em aveia por CECATO et al. (2001), que, avaliando genótipos de aveia submetidos a dois cortes, observaram valores médios entre 15,94 e $19,66 \%$ de proteína bruta. ROSO et al. (2000) encontraram valores médios de $20,3 \%$ de PB para a mistura de aveia-preta e azevém sob pastejo, que são as forrageiras de inverno mais utilizadas no estado do Rio Grande do Sul.

A composição mineral da forragem não variou com as doses de nitrogênio (Tabela 6). Entretanto, a densidade de semeadura afetou os teores de fósforo, potássio e cálcio. Na densidade de 400 sementes $/ \mathrm{m}^{2}$ foi observado maior teor de fósforo, potássio e cálcio quando comparado à densidade de 500 sementes/ $\mathrm{m}^{2}$. A redução da concentração de nutrientes na maior densidade, possivelmente ocorreu devido à competição por nutrientes do solo. A composição mineral da forragem também foi afetada pelo manejo dos cortes. Os teores de fósforo, potássio e magnésio foram maiores no segundo corte. Esse comportamento pode ser explicado, em parte, pelo menor intervalo entre cortes (35 dias). Este menor intervalo entre cortes, possivelmente permitiu maior participação de brotações jovens, que apresentam teores maiores de minerais. 


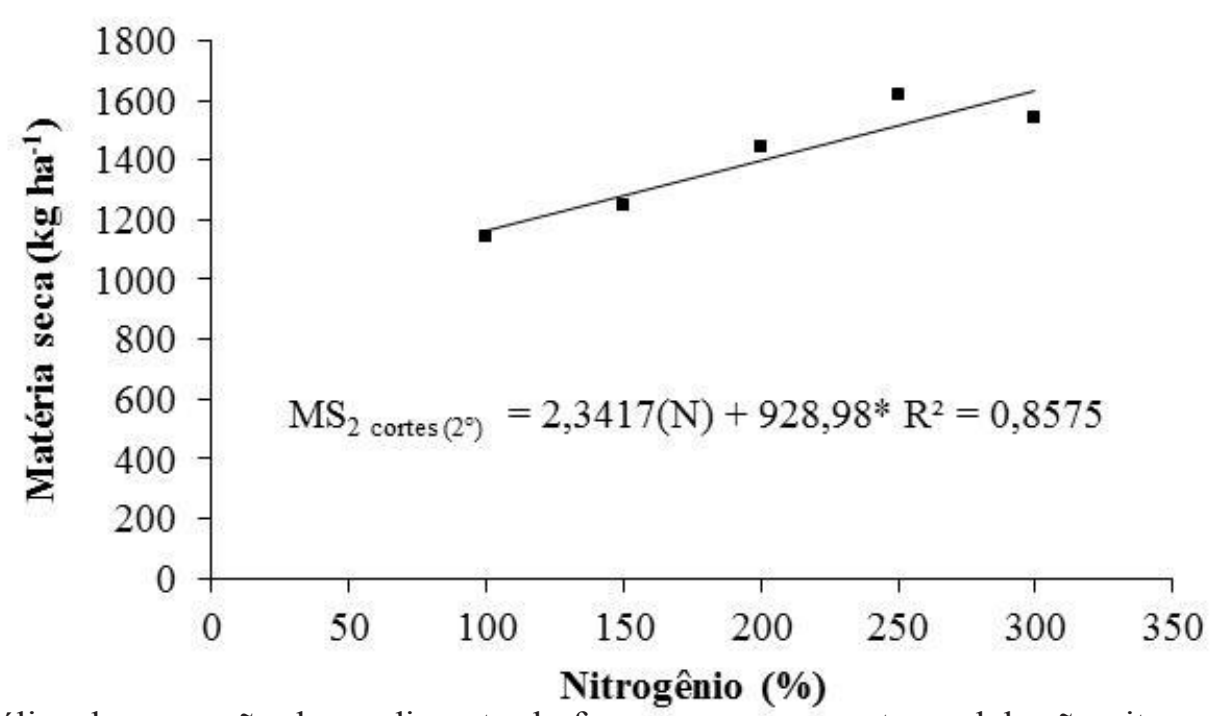

Figura 2. Análise de regressão do rendimento de forragem em resposta a adubação nitrogenada e manejo de corte em trigo de duplo propósito BRS Tarumã.

Figure 2. Regression analysis of forage yield in different nitrogen levels and harvesting management of BRS Tarumã dual-purpose wheat.

*Significativo a $5 \%$ de probabilidade. MS, matéria seca; N, nitrogênio.

Tabela 6. Proteína bruta e composição da fração mineral em trigo de duplo propósito BRS Tarumã.

Table 6. Crude protein content and mineral composition of BRS Tarumã dual-purpose wheat.

\begin{tabular}{|c|c|c|c|c|c|}
\hline Dose de N (\%) & PB (\%) & $\mathrm{P}\left(\mathrm{g} \mathrm{kg}^{-1}\right)$ & $\mathrm{K}\left(\mathrm{g} \mathrm{kg}^{-1}\right)$ & $\mathrm{Ca}\left(\mathrm{g} \mathrm{kg}^{-1}\right)$ & $\operatorname{Mg}\left(\mathrm{g} \mathrm{kg}^{-1}\right)$ \\
\hline 100 & 24,7 & 3,47 & 36,90 & 4,80 & 1,80 \\
\hline 150 & 23,7 & 3,50 & 35,50 & 4,65 & 1,83 \\
\hline 200 & 24,0 & 3,35 & 37,72 & 4,81 & 1,84 \\
\hline 250 & 24,4 & 3,53 & 39,72 & 4,76 & 1,82 \\
\hline 300 & 24,8 & 3,25 & 39,01 & 4,48 & 1,81 \\
\hline Densidade de semeadura $\left(\mathrm{m}^{2}\right)$ & PB (\%) & $\mathrm{P}\left(\mathrm{g} \mathrm{kg}^{-1}\right)$ & $\mathrm{K}\left(\mathrm{g} \mathrm{kg}^{-1}\right)$ & $\mathrm{Ca}\left(\mathrm{g} \mathrm{kg}^{-1}\right)$ & $\operatorname{Mg}\left(\mathrm{g} \mathrm{kg}^{-1}\right)$ \\
\hline 400 & 24,43 & $3,55 \mathrm{~A}$ & $39,05 \mathrm{~A}$ & $4,81 \mathrm{~A}$ & 1,84 \\
\hline 500 & 24,20 & $3,28 \mathrm{~B}$ & $36,25 \mathrm{~B}$ & $4,58 \mathrm{~B}$ & 1,80 \\
\hline Manejo & PB (\%) & $\mathrm{P}\left(\mathrm{g} \mathrm{kg}^{-1}\right)$ & $\mathrm{K}\left(\mathrm{g} \mathrm{kg}^{-1}\right)$ & $\mathrm{Ca}\left(\mathrm{g} \mathrm{kg}^{-1}\right)$ & $\mathrm{Mg}\left(\mathrm{g} \mathrm{kg}^{-1}\right)$ \\
\hline 1 corte & 24,43 & $3,11 \mathrm{~B}$ & $36,24 \mathrm{~B}$ & 4,86 & $1,72 \mathrm{~B}$ \\
\hline 2 cortes $\left(1^{\circ}\right)$ & 24,44 & $2,95 \mathrm{~B}$ & $35,24 \mathrm{~B}$ & 4,72 & $1,77 \mathrm{~B}$ \\
\hline 2 cortes $\left(2^{\circ}\right)$ & 24,13 & 4,27 A & $41,87 \mathrm{~A}$ & 4,51 & $1,98 \mathrm{~A}$ \\
\hline CV (\%) & 12,4 & 18,41 & 14,18 & 22,11 & 11,40 \\
\hline $\mathrm{F}$ (doses de $\mathrm{N}$ ) & $0,29^{\text {ns }}$ & $1,02^{\mathrm{ns}}$ & $0,64^{\mathrm{ns}}$ & $0,57^{\text {ns }}$ & $1,03^{\mathrm{ns}}$ \\
\hline $\mathrm{F}$ (densidade) & $0,21^{\text {ns }}$ & $7,77^{*}$ & $6,68^{*}$ & $6,24 *$ & $2,71^{\mathrm{ns}}$ \\
\hline$F_{\text {(Manejo) }}$ & $0,19^{\text {ns }}$ & $42,84^{*}$ & $16,65^{*}$ & $1,82^{\mathrm{ns}}$ & $15,29^{*}$ \\
\hline
\end{tabular}

Médias seguidas da mesma letra maiúscula nas colunas não diferem $(\mathrm{p}<0,05)$ significativamente pelo teste Tukey.

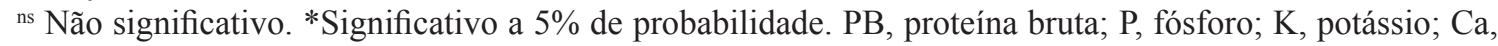
cálcio; Mg, Magnésio. 
Os valores observados por MEINERZ et al. (2011), avaliando genótipos de cereais de duplo propósito submetidos a três cortes, observaram valores médios superiores para fósforo, cálcio e magnésio e inferiores para potássio aos encontrados no presente trabalho. Segundo os autores, a composição mineral da forragem foi elevada e diminuiu com o número de cortes, resultado não observado no presente trabalho, onde os teores aumentaram ou se mantiveram iguais no segundo corte.

O manejo correto da densidade de semeadura, adubação nitrogenada e do número de cortes, pode viabilizar o uso do trigo de duplo propósito BRS Tarumã e o sistema de integração lavoura pecuária na região Meio Oeste Catarinense. Segundo MEINERZ et al. (2012), BRS Tarumã é o genótipo que apresenta melhor equilíbrio entre produtividade de forragem e grãos, e o mais indicado para o manejo de duplo propósito. Assim, o manejo adequado do trigo de duplo propósito BRS Tarumã para produção de forragem não inviabilizaria a produção de grãos.

\section{CONCLUSÃO}

O segundo corte proporcionou maior acúmulo de forragem, não causou prejuízos à composição mineral e ao teor de proteína bruta da forragem, não reduziu a produtividade, e, portanto, viabiliza o seu aproveitamento para duplo propósito. No manejo com dois cortes a adubação nitrogenada deve ser superior ( 2,5 vezes) à adubação recomendada para o trigo para grão, pois aumenta a produção de forragem.

A maior densidade de semeadura promoveu incrementos na produtividade de grãos e não alterou a produção de forragem para o segundo corte. No entanto, o aumento da população mostrou tendência de aumento na produção de forragem se realizado apenas um corte. O teor de proteína bruta na forragem não foi alterado pela adubação nitrogenada nas condições do experimento, porém foi elevado em relação a outras forragens e pode ser uma fonte importante na produção animal durante o período de outono-inverno para a região.

\section{REFERÊNCIAS}

AOAC - Association of Official Analytical Chemists. 1995. Official methods of analysis. 16.ed. Washington, DC: Association of Official Analytical Chemists. 1025p. BALBINOT JUNIOR AA et al. 2009. Integração lavourapecuária: intensificação de uso de áreas agrícolas. Ciência
Rural 39: 1925-1933.

BORTOLINI PC et al. 2004. Cereais de inverno submetidos ao corte no sistema de duplo propósito. Revista Brasileira de Zootecnia 33: 45-50.

CECATO U et al. 2001. Produção e composição química em cultivares e linhagens aveia (Avena spp.). Acta Scientiarum 23: 775-780.

CHRISTIANSEN S et al. 1989. Spring and fall cattle grazing effects on components and total grain yield of winter wheat. Agronomy Journal 81: 145-150

DEL DUCA L de JA et al. 2000. Experimentação de genótipos de trigo para duplo propósito no Paraná, em 1999. Passo Fundo: Embrapa Trigo. 28p. (Boletim de pesquisa e desenvolvimento, 6).

FEROLLA FS et al. 2007. Produção de matéria seca, composição da massa de forragem e relação lâmina foliar/ caule + bainha de aveia-preta e triticale nos sistemas de corte e de pastejo. Revista Brasileira de Zootecnia 36: 1512-1517.

MARTIN TN et al. 2010. Fitomorfologia e produção de cultivares de trigo duplo propósito em diferentes manejos de corte e densidades de semeadura. Ciência Rural 40: 1695-1701.

MCRAE F. 2003. Crop agronomy and grazing management of winter cereals. New South Wales Agriculture 59: 59-69. MEINERZ GR et al. 2012. Produtividade de cereais de inverno de duplo propósito na depressão central do Rio Grande do Sul. Revista Brasileira de Zootecnia 41: 873882.

MEINERZ GR et al. 2011.Valor nutritivo da forragem de genótipos de cereais de inverno de duplo propósito. Revista Brasileira de Zootecnia 40: 1173-1180.

SCHEFFER-BASSO SM et al. 2001. Potencial de genótipos de aveia para duplo-propósito. Revista Brasileira de Agrociência 7: 22-28.

ROSO C \& RESTLE J. 2000. Aveia preta, triticale e centeio em mistura com azevém. 2. Produtividade Animal e Retorno Econômico. Revista Brasileira de Zootecnia. 29: 85-93.

TEDESCO MJ et al. 1995. Análise de solo, plantas e outros materiais. 2.ed. Porto Alegre: UFRGS. 147p. (Boletim técnico, 5)

VALÉRIO IP et al. 2008. Desenvolvimento de afilhos e componentes do rendimento em genótipos de trigo sob diferentes densidades de semeadura. Pesquisa Agropecuária Brasileira 43: 319-326.

WENDT W et al. 2006. Manejo na cultura do trigo com finalidade de duplo propósito-forragem e grãos. Pelotas: Embrapa. 2p. (Comunicado técnico 141).

ZAFFARONI E et al. 1998. Análise de caminho nos componentes do rendimento de genótipos de arroz no Rio Grande do Sul. Pesquisa Agropecuária Brasileira 33: 4348.

Revista de Ciências Agroveterinárias, Lages, v.16, n.4, 2017375 